\title{
Disaster Planning for Pediatrics
}

\author{
Richard D Branson MSc RRT FAARC
}

\author{
Introduction \\ Disaster Relevant Issues Secondary to Differences in Pediatric Physiology \\ Specific Issues Related to Potential Exposures \\ Are Disasters Predominantly Affecting Children Likely? \\ Assessment of Disaster Preparedness in the United States \\ A Pediatric Patient in the Community Hospital ED: The " $n$-of-1" Disaster \\ Ventilators in the Strategic National Stockpile and Pediatrics \\ The National Ventilator Survey \\ The National Commission on Children and Disasters \\ Summary
}

\begin{abstract}
Natural and man-made disasters are inevitable and appear to be more common in the current age. Substantial time and effort have been invested and millions of dollars spent on disaster prevention and management. An important oversight in this planning has been the special needs of children. The vulnerability of children and their physiologic characteristics place them at increased risk during a disaster. Importantly, reunification with family and assurance of safety in this vulnerable group is a priority. This paper addresses issues related to pediatric needs, the medical system's shortcomings in caring for children, and recommendations for action. Key words: disaster; preparedness; pediatric; catastrophe. [Respir Care 2011;56(9):1457-1463. (C) 2011 Daedalus Enterprises]
\end{abstract}

'Twas in another lifetime, one of toil and blood When blackness was a virtue and the road was full of mud I came in from the wilderness, a creature void of form

"Come in," she said, "I'll give you shelter from the storm" -Bob Dylan, Shelter from the Storm

\section{Introduction}

Disaster-management issues following man-made and natural catastrophes have gripped the world in the last

Mr Branson is affiliated with the Division of Trauma and Critical Care, Department of Surgery, University of Cincinnati Medical Center, University of Cincinnati College of Medicine, Cincinnati, Ohio.

Mr Branson presented a version of this paper at the 47th RESPIRATORY CARE Journal Conference, "Neonatal and Pediatric Respiratory Care: What Does the Future Hold?" held November 5-7, 2010, in Scottsdale, Arizona. decade, since the terrorist attacks of September 11th, 2001. A recent combined natural disaster (earthquake and tsunami) and nuclear power plant emergency (radiation release) in Japan has only heightened concerns. While disaster-management relies on the development of systems and coordination of pre-hospital and hospital procedures, there is often a missing element: disaster planning for children. Children in a disaster pose unique problems and issues for the healthcare community. The earthquake in Haiti highlighted distinctive pediatric concerns. From phys-

\footnotetext{
Mr Branson has disclosed relationships with Covidien, CareFusion, Ikaria, Advanced Circulatory Systems, and General Electric.

Correspondence: Richard D Branson MSc RRT FAARC, Department of Surgery, University of Cincinnati Medical Center, PO Box 670558, 231 Albert Sabin Way, Cincinnati OH 45267-0558. E-mail: richard.branson@ uc.edu.
}

DOI: $10.4187 /$ respcare. 01405 
Table 1. Unique Consequences in Children During a Disaster, Owing to Anatomic and Physiologic Characteristics

\begin{tabular}{|c|c|c|}
\hline Characteristic & Cause & Consequences \\
\hline Larger head for a given body weight & Higher center of gravity & More likely to suffer head injuries and falls \\
\hline Greater skin surface for body weight & Evaporative heat and water losses & Hypothermia and dehydration \\
\hline Small blood vessels & Relative size with younger age & $\begin{array}{l}\text { Difficult venous access, more difficult fluid } \\
\text { and medication delivery }\end{array}$ \\
\hline $\begin{array}{l}\text { Closer proximity of solid organs with less } \\
\text { bony protection }\end{array}$ & Relative size with younger age & Greater chance of multi-organ injuries \\
\hline Wide range of normal vital signs & $\begin{array}{l}\text { Large differences in size, weight, and normal } \\
\text { values }\end{array}$ & $\begin{array}{l}\text { Difficult to determine normal values for a } \\
\text { given individual, particularly for clinicians } \\
\text { more accustomed to caring for adult patients }\end{array}$ \\
\hline Rapid heart and respiratory rate & $\begin{array}{l}\text { Normal physiologic variables based on age } \\
\text { and weight }\end{array}$ & $\begin{array}{l}\text { Faster intake of airborne agents and } \\
\text { dissemination to tissues }\end{array}$ \\
\hline $\begin{array}{l}\text { Wide range of weight across pediatric age } \\
\text { range }\end{array}$ & $\begin{array}{l}\text { Normal physiologic variables based on age } \\
\text { and weight }\end{array}$ & Greater likelihood of medication errors \\
\hline Shorter height & Closer to the ground & $\begin{array}{l}\text { Greater exposure to chemical and biologic } \\
\text { toxins that settle near the ground due to } \\
\text { higher density }\end{array}$ \\
\hline Often found in groups & Daycare and school & More likely to see multiple casualties \\
\hline Immature cognitive and coping skills & $\begin{array}{l}\text { Age and experience, psychological } \\
\text { development }\end{array}$ & $\begin{array}{l}\text { Less likely to flee from danger, inability to } \\
\text { cope, inability to care for themselves, find } \\
\text { sustenance, and avoid danger }\end{array}$ \\
\hline
\end{tabular}

iologic differences to the need for reuniting with families, pediatric problems pose particular challenges.

\section{Disaster Relevant Issues Secondary to Differences in Pediatric Physiology}

Compared to adults, the physiologic and psychological characteristics of children in a disaster have greater variability and distinct disadvantages. ${ }^{1}$ Anatomic differences place the pediatric disaster victim in particular peril. The head of the pediatric patient represents a substantially greater portion of the total body surface area. This anatomic difference predisposes children to head injury and falls, secondary to a high center of gravity. The smaller body surface area also places the solid organs in closer proximity with less protection, owing to more compliant bony structures. Children can suffer substantial thoracic organ damage with no evidence of rib fractures. The wide range of normal vital signs in children-often lumped together regardless of size, as ages 1-16 years-confounds the definition of normal. The definition of "pediatric" is quite variable and spans the range from infants to 14-yearolds with physical attributes similar to adults. Smaller patients have faster heart rate and respiratory rate, which increase exposure and systemic distribution of chemical and biologic agents.

The wide variability in weight of pediatric patients increases the likelihood of medication errors. In adults, a single dose is typically constant or based on predicted body weight. These formulas do not always apply to children. Drug metabolism in children can be quite variable, compared to adults, making correct dosage critical. Children suffer greater evaporative heat and water loss due to exposure (greater risk of dehydration) and may absorb greater amounts of chemical toxins, owing to the greater skin surface area for body weight. In the smallest patients, intravenous access is a challenge, particularly for adult practitioners. Fluid replacement in children is more important, as fluid reserves are small, compared to adults.

Because children are closer to the ground, they are at risk for greater exposure to airborne agents, which tend to be more dense than ambient air, settling closer to the ground. Children are also less likely to attempt to escape dangerous environments, owing to fear, perception of danger, or underdeveloped motor skills. Children also lack coping skills and self-preservation experience. Because children depend on adults for direction and sustenance, they are at risk if left alone. ${ }^{2-5}$ Table 1 highlights these issues.

\section{Specific Issues Related to Potential Exposures}

In a disaster in which infrastructure is interrupted, foodand water-borne illnesses (eg, botulinum toxin, salmonella) pose a greater risk of dehydration in children. Blistering agents (eg, mustard gas) result in greater toxicity. Nerve agents (eg, sarin) may result in excessive secretion and airway occlusion due to smaller airway diameter. Seizure activity would be greater in children, secondary to greater absorption of agents. In the case of radiation exposure, the thin skin of children allows greater absorption, and exposure to radiation in food and water causes greater risk of thyroid and other cancers. Smallpox vaccination in cases 
of outbreaks has greater complications in children, and the vaccinated are more likely to expose the unvaccinated.

\section{Are Disasters Predominantly Affecting Children Likely?}

Children represent a smaller percentage of the population than adults, which raises the question of the probability of predominant pediatric patients in a disaster. Children are often gathered in groups at day-cares, schools, and attractions, which increases the risk of a surge of pediatric patients. ${ }^{6,7}$ In recent years, several terrorist attacks have resulted in numerous pediatric patients. The day-cares at both the World Trade Centers in New York, and at the Alfred P Murrah Federal Building in Oklahoma were damaged and there were a number of injured children. ${ }^{89}$ The Beslan hostage tragedy in North Ossetia occurred in a school, and of 334 dead, 186 were children. ${ }^{10}$ Injuries from the earthquake in Haiti were predominantly orthopedic, but $40 \%$ of the casualties were children. ${ }^{11}$ The recent earthquake, tsunami, and nuclear disaster in Japan probably caused a large number of pediatric injuries and deaths; the number of known dead and missing exceeds 20,000, and the number of children involved is unknown. When a tornado struck a school in Enterprise, Alabama, there were 50 deaths and more than 50 injured children. These events highlight that children clustered in schools are at substantial risk and that these events can create a pediatric surge. The next disaster with a large number of injuries in children is not a question, but simply a matter of time.

\section{Assessment of Disaster Preparedness in the United States}

A number of limitations have been identified in the United States' preparedness for a pediatric surge following a disaster. A 2003 report from the Institute of Medicine provided some sobering thoughts on the state of emergency medical services and hospital emergency departments (EDs). ${ }^{12}$ Illustrative findings include an increase in ED visits at a time when hospitals closed 425 EDs due to financial instability. ED overcrowding leads to diversion of emergency medical services units to less prepared hospitals and increases the risk of errors and poor outcomes. Emergency-medical-services public safety departments are over-taxed and underfunded. Shortage of healthcare providers has been an issue, but the recent economic depression has brought many healthcare professionals back into the workforce.

The capability of adult and general hospitals to care for pediatric patients in a disaster scenario is uncertain. This is unfortunate, given that children account for 25-30 million ED visits yearly. Complicating matters, $90 \%$ of pediatric visits are to general hospital EDs, yet $50 \%$ of these hospitals see $<10$ children in a day. This limited exposure to pediatric patients results in a gap in experience and the staff's comfort with children. Additionally, few general hospitals provide training in pediatric emergencies, and less than $6 \%$ possess a full complement of child-appropriate equipment, medications, and supplies. ${ }^{13-15}$

\section{A Pediatric Patient in the Community Hospital ED: The " $n$-of-1" Disaster}

Many adult caregivers in the community can relate to the " $n$-of-1" disaster. The toddler with croup or epiglottitis, the infant with bronchiolitis, and the 12-year-old with status asthmaticus all can bring the adult ED to its knees. Determination of appropriate medication dosage and availability of age-appropriate equipment are critical to successful care of the child. However, the cost to maintain a cache of pediatric equipment that might be used only in 3 or 4 emergency situations per year is a fiscal challenge for hospitals. Endotracheal intubation, venous access, and mechanical ventilation may all become "foreign" procedures. ${ }^{16,17}$

The Broselow pediatric emergency tape was designed to alleviate a number of challenges in emergency care of children. ${ }^{18}$ The Broselow tape is a $146.5 \mathrm{~cm}$ strip of laminated paper divided into colored regions that correspond to patient height. The colors are subdivided into different kilogram weights. For each weight the tape shows appropriate medication dosages and device sizes for oxygendelivery devices, resuscitation bags, endotracheal tubes, etcetera. The Broselow tape is designed for children $\leq 12$ years, to a maximum weight of $36 \mathrm{~kg}$, so it is for a limited range of pediatric patients, relative to what we might consider a child ( $<100$ pounds). Typically, the tape goes along with a set of pediatric equipment and medications, organized by their Broselow-Luten colors on the colored drawers on crash carts; colored pouches are used in ambulances. The system uses specially designed syringes that match the colors to age-appropriate concentrations and dosages, which reduces the risk of miscalculation and medication errors. Drug algorithms for resuscitation are also included for each color category. Most of the investigations of the Broselow tape in the pediatric ED have found the tape superior to physician estimates, although there appears to be room for improvement. ${ }^{19-22}$

\section{Ventilators in the Strategic National Stockpile and Pediatrics}

The strategic national stockpile is a cache of medical equipment maintained by the Centers for Disease Control and Prevention. A component of the stockpile is a cache of approximately 10,000 ventilators, which include the Im- 
Table 2. Stockpile Ventilator Performance Relevant to Pediatric Use

\begin{tabular}{|c|c|c|c|}
\hline & Impact 754 & LP10 & LTV-1200 \\
\hline Ventilation modes & CMV, SIMV & CMV & CMV, SIMV, PSV, CPAP \\
\hline \multirow[t]{2}{*}{ Breath types } & Volume control & Volume control & Volume control \\
\hline & $\begin{array}{l}\text { Volume control with electronic } \\
\text { pressure limit }\end{array}$ & $\begin{array}{l}\text { Volume control with mechanical } \\
\text { pressure limit (the pressure-limiting } \\
\text { feature is only intended for use } \\
\text { with an uncuffed tube) }\end{array}$ & Pressure control \\
\hline $\begin{array}{l}\text { Minimum tidal volume in volume } \\
\text { control mode }\end{array}$ & $\begin{array}{l}50 \mathrm{~mL} \text { with } 50 \text { psig air and oxygen, } \\
300 \mathrm{~mL} \text { running on the internal } \\
\text { compressor }\end{array}$ & $50 \mathrm{~mL}$ & $100 \mathrm{~mL}$ \\
\hline Flow during spontaneous breathing & $60 \mathrm{~L} / \mathrm{min}$ & None & $1-160 \mathrm{~L} / \mathrm{min}$ \\
\hline $\mathrm{F}_{\mathrm{IO}_{2}}$ & $0.21-1.0$ & $\begin{array}{l}\text { Depends on reservoir size, oxygen } \\
\text { flow, and minute ventilation }\end{array}$ & $0.21-0.95$ \\
\hline $\begin{array}{l}\mathrm{CMV}=\text { continuous mandatory ventilation } \\
\mathrm{SIMV}=\text { synchronized intermittent mandatory } \mathrm{v} \\
\mathrm{PSV}=\text { pressure support ventilation } \\
\mathrm{CPAP}=\text { continuous positive airway pressure } \\
\mathrm{F}_{\mathrm{IO}_{2}}=\text { fraction of } \mathrm{F}_{\mathrm{IO}_{2}}\end{array}$ & & & \\
\hline
\end{tabular}

pact 754, the Puritan Bennett LP10, and the Pulmonetics LTV-1200. Each ventilator is kitted with disposable supplies, including adult and pediatric circuits, bacterial filters, adult and pediatric heat-and-moisture exchangers, a low-flow oxygen reservoir kit, metered-dose inhaler adapter, suction catheters, and (only with the LP10) a spring-loaded PEEP valve. Each of these ventilators has strengths and weaknesses, related to battery life, gas consumption, and work of breathing. ${ }^{23-27}$ Table 2 compares these devices relative to pediatric application.

The Impact 754 has a minimum tidal volume $\left(\mathrm{V}_{\mathrm{T}}\right)$ of $50 \mathrm{~mL}$ when running on $50 \mathrm{psig}$ air or oxygen. When running on the internal compressor, the manual recommends that a $\mathrm{V}_{\mathrm{T}}<300 \mathrm{~mL}$ should not be provided because of variability in volume delivery. During spontaneous breathing, the Impact 754 has a pre-set flow of $60 \mathrm{~L} /$ min, which can be adjusted in the range $10-60 \mathrm{~L} / \mathrm{min}$. However, that value is fixed and cannot adapt to changes in patient demand. A pressure limit can be set with the plateau control, which stops flow if the pressure exceeds the set threshold. The flow remains constant in the volume-control mode, which creates a pressure-limited, flowcontrolled, time-cycled breath. This may be useful in ventilating pediatric patients when the compressor is engaged.

The LP10 is a home-care ventilator that uses a piston for constant volume delivery. The only available mode is continuous mandatory ventilation. In the IMV mode the patient breathes room air through the back of the piston. A continuous-flow system can be attached to assist with reducing the work of breathing and maintain an elevated $\mathrm{F}_{\mathrm{IO}_{2}}$. The LP10 has a mechanical pressure limit, controlled by an adjustable, spring-loaded valve that vents gas to the atmosphere when the threshold is reached. This feature, however, is only to be used when the system has a known leak.

The pressure-limited functioning of the Impact 754 and LP10 bear further explanation. These modes deliver a volume and flow as set in the volume-control mode. With the LP10, gas consumption is increased relative to the patient's minute ventilation. With the Impact 754, gas consumption is similar to the patient's minute ventilation, because gas is not lost to the atmosphere. Most importantly, the Impact 754 and LP10 do not deliver pressurecontrol breaths with a variable decelerating-flow output able to adapt to patient demand, and thus do not provide the reported advantages of pressure-control ventilation on reducing the work of breathing. The common ventilator circuit used with the Impact 754 and LP10 represent an advantage, as these circuits with a built-in exhalation valve are commonly present in most hospitals. However, in pediatric patients the tubing between the exhalation valve and the endotracheal tube should be removed to diminish dead space.

The LTV-1200 is the newest addition. It was developed 10 years after the Impact 754 and LP10. The LTV-1200 features continuous mandatory ventilation, synchronized intermittent mandatory ventilation, pressure support ventilation, and CPAP. The minimum $\mathrm{V}_{\mathrm{T}}$ is $50 \mathrm{~mL}$, and pressure control ventilation is available in both continuous mandatory ventilation and synchronized intermittent mandatory ventilation. The device can be pressure or flow triggered, and it measures the delivered and exhaled $V_{T}$ 


\section{Disaster Planning for Pediatrics}

Table 3. Recommendations of the National Commission on Children and Disasters

Disaster Management and Recovery

Establish a focus on children and disasters within the Federal Emergency Management Agency and the White House, supported by policy and operational expertise from across the federal government, non-federal partners, and relevant non-governmental organizations.

Incorporate meeting the needs of children as a distinct priority throughout the base disaster-planning documents and relevant grant programs.

Include children in relevant target capabilities, preparedness training, and exercises, with specific target outcomes and performance measures.

Accelerate the development of a National Disaster Recovery Strategy, with an explicit emphasis on addressing the immediate and long-term physical and mental health, educational, housing, and human-services recovery needs of children.

Mental Health

Integrate mental and behavioral health for children into all public health and medical preparedness and response activities.

Enhance the research agenda for children's disaster mental and behavioral health, including psychological first aid, cognitive and behavioral interventions, social support interventions, and bereavement counseling and support.

Enhance pediatric disaster mental and behavioral health training for professionals and paraprofessionals, including psychological first aid, cognitive and behavioral interventions, social support interventions, and bereavement counseling and support.

Child Physical Health and Trauma

Ensure availability of and access to pediatric medical countermeasures at the federal, state, and local level for chemical, biological, radiological, nuclear, and explosive threats.

Expand the medical capabilities of all federally funded response teams through the comprehensive integration of pediatric-specific training, guidance, exercises, supplies, and personnel.

Ensure that all healthcare professionals who may treat children during an emergency have adequate pediatric disaster clinical training specific to their roles.

Provide funding for a formal regionalized pediatric system of care for disasters.

Ensure access to physical and mental health services for all children during recovery from disaster.

Emergency Medical Services and Pediatric Transport

Improve the capability of emergency medical services to transport pediatric patients and provide comprehensive pre-hospital pediatric care during daily operations and disasters.

Disaster Case Management

Establish a holistic federal disaster case-management program, with an emphasis on achieving tangible positive outcomes for all children and families within a Presidentially-declared disaster area.

Child Care

Require disaster planning capabilities for child care providers.

Improve capacity to provide child care services in the immediate aftermath of and recovery from a disaster.

Elementary and Secondary Education

Establish a school disaster preparedness program and appropriate funds to the United States Department of Education for a dedicated and sustained funding stream to all state education agencies. Funding should be used for state-level and district-level disaster response planning, training, exercises, and evaluation that are coordinated with state and local plans and activities.

Enhance the ability of school personnel to support children who are traumatized, grieving, or otherwise recovering from a disaster.

Child Welfare and Juvenile Justice

Provide guidance, technical assistance, and model plans to assist state and local child welfare agencies in meeting current applicable disaster planning requirements and further require collaboration with state and local emergency management, courts, and other key stakeholders.

Conduct a national assessment of disaster planning and preparedness among state and local juvenile justice systems to inform the development of comprehensive disaster plans.

Sheltering Standards, Services, and Supplies

Provide a safe and secure mass care shelter environment for children, including appropriate access to essential services and supplies.

Housing

Prioritize families with children for disaster housing assistance and expedited transition into permanent housing, especially families with children who have disabilities or other special health, mental health, or educational needs.

Evacuation

Develop a standardized, interoperable national evacuee tracking and family-reunification system that ensures the safety and well-being of children.

(Adapted from Reference 29.)

via a fixed-orifice pneumotachometer in the circuit Ypiece. During spontaneous breathing, a flow of up to $160 \mathrm{~L} /$ min is available. The LTV-1200 is the most pediatricfriendly of the ventilators in the strategic national stockpile. Disadvantages include short battery life and high gas consumption when the bias flow is in the default position of
$10 \mathrm{~L} / \mathrm{min}$. The LTV-1200 also cannot deliver an $\mathrm{F}_{\mathrm{IO}_{2}}>$ 0.95 . The use of the turbine to create the power for ventilation results in some dilution of oxygen. The accuracy of the $\mathrm{V}_{\mathrm{T}}$ delivery and volume measurement with low $\mathrm{V}_{\mathrm{T}}$ is also an issue. The reported accuracy of volume delivery is $\pm 10 \%$ or $10 \mathrm{~mL}$, and the accuracy of volume monitoring 
is $\pm 15 \%$ or $15 \mathrm{~mL}$, which can result in important differences between the desired and actual $\mathrm{V}_{\mathrm{T}}$, complicated by volume monitoring variability and loss of volume to tubing compliance.

The nuances of these ventilators, particularly in application to pediatric patients, admonishes us all to RTM (read the manual). It is incumbent on respiratory therapists to be familiar with these devices in the event of a masscasualty event. In particular, the use of these devices in pediatrics is important. Of the 3 ventilators in the strategic national stockpile, the LTV-1200 is the most pediatricfriendly.

\section{The National Ventilator Survey}

The National Ventilator Survey was a joint venture between the Department of Health and Human Services and the American Association for Respiratory Care (AARC) ${ }^{28}$ to determine the types of ventilators owned by United States hospitals. The survey was validated in Ohio and found to be accurate and user-friendly. The Web-based survey was conducted during the second quarter of 2010. The list of surveyed hospitals was obtained from the American Hospital Association. Hospitals that did not respond were called and encouraged to participate. In some cases the AARC caller recorded the information and entered the data in the database. A remarkable $75 \%$ response rate was achieved. This number accounted for $84 \%$ of ICU beds. This finding suggests that larger hospitals with greater numbers of ventilators responded more than did smaller hospitals.

Of the 52,118 full-feature mechanical ventilators reported by the respondent hospitals, 24,204 (46\%) were considered pediatric/neonatal capable. This is probably because a greater number of ventilators than ever before are capable of "cradle-to-grave" support. In the survey, "pediatric/neonatal-capable" required that the ventilator actually had the required software and hardware (eg, proximal flow sensors). Ventilators that could be made pediatriccapable but did not currently have the required software and hardware were not counted as pediatric-capable, because it is unlikely that the required upgrades would be made in a disaster scenario. Based on the reported number of 52,118, the estimate of the total number of full-feature ventilators in United States hospitals came to 62,188 . The median number of full-feature ventilators per 100,000 people for a given state was 19.7 (range 11.9-77.6). The median number of pediatric-capable ventilators per 100,000 people $<14$ years old was 52.3 (range 22.1-206.2). Including all ventilators (including noninvasive, transport, et cetera), it was estimated that there are a total of 98,738 ventilators in all the United States acute-care hospitals. The study concluded that the number of mechanical ventilators per United States population was substantially greater than other countries, and that there are considerably more pediatric-capable ventilators than there are for adults, on a population-adjusted basis. While only experience will determine if the number of ventilators owned by hospitals and available in the strategic national stockpile is sufficient, the fact that, to date, no incident has resulted in a reported ventilator shortage suggests that future local, state, and national ventilator purchases should be judicious. The money may be better spent on training and other priorities.

\section{The National Commission on Children and Disasters}

In 2009 the federal government convened a panel of experts, the National Commission on Children and Disasters (http://www.childrenanddisasters.acf.hhs.gov), to consider the issue of children in disasters and the current state of disaster-response readiness for the pediatric population. Table 3 shows the panel's recommendations. ${ }^{29}$ Some common-sense recommendations are often overlooked and deserve to be pointed out. The Commission reported that the current state of post-disaster animal welfare and reunification with owners has received more attention and planning than that for children. Stockpiling requires not only medical equipment and drugs, but simple products such as diapers. Whenever possible, children should be reunited with their families and sheltered together. The shelters should protect individuals from exploitation and violence. Daily training in pediatric emergency care is the best preparation.

\section{Summary}

Children represent nearly a quarter of the population. However, preparation and countermeasures, physical and psychological, specific to children are sorely lacking.

\section{REFERENCES}

1. Becker BM. Children and disaster. In: Ciottone G, editor. Disaster medicine. Philadelphia: Elsevier Mosby; 2006:51-58.

2. Markenson D, Reynolds S. The pediatrician and disaster preparedness. Pediatrics 2006;117(2):e340-e362.

3. American Academy of Pediatrics Committee on Pediatric Emergency Medicine, American Academy of Pediatrics Committee on Medical Liability, Task Force on Terrorism. The pediatrician and disaster preparedness. Pediatrics 2006;117:560-565.

4. Redlener I, Markenson D. Disaster and terrorism preparedness: what pediatricians need to know. Dis Mon 2004;50(1):6-40.

5. Garrett AL, Grant R, Madrid P, Brito A, Abramson D, Redlener I. Children and megadisasters: lessons learned in the new millennium. Adv Pediatr 2007;54:189-214.

6. Allen GM, Parrillo SJ, Will J, Mohr JA. Principles of disaster planning for the pediatric population. Prehosp Disaster Med 2007;22(6): 537-540. 
7. A National Consensus Conference: Pediatric preparedness for disasters and terrorism. New York: Columbia University, Mailman School of Public Health; 2003.

8. Cushman JG, Pachter HL, Beaton HL. Two New York City hospitals' surgical response to the September 11, 2001, terrorist attack in New York City. J Trauma 2003;54(1):147-54.

9. The Oklahoma City bombing: mass casualties and the local hospital response. Hosp Secur Saf Manage 1995;16(5):5-10.

10. Vetter S, Dulaev I, Mueller M, Henley RR, Gallo WT, Kanukova Z. Impact of resilience enhancing programs on youth surviving the Beslan school siege. Child Adolesc Psychiatry Ment Health 2010;22:4-11.

11. Shah SD, Aligne CA. Pediatrics in the community: the Haiti earthquake. Pediatr Rev 2011;32(1):34.

12. National Academies Institute of Medicine. Consensus report: Emergency medical services at the crossroads. June 13, 2006. http:// www.iom.edu/Reports/2006/Emergency-Medical-Services-At-theCrossroads.aspx. Accessed July 8, 2011.

13. Gausche-Hill M. Pediatric disaster preparedness: are we really prepared? J Trauma 2009;67(2 Suppl):S73-S76.

14. Gausche-Hill M, Schmitz C, Lewis RJ. Pediatric preparedness of US emergency departments: a 2003 survey. Pediatrics 2007;120(6):12291237.

15. Gausche-Hill M, Wiebe RA. Guidelines for preparedness of emergency departments that care for children: a call to action. Pediatrics 2001;107(4):773-774.

16. Shah AN, Frush K, Luo X, Wears RL. Effect of an intervention standardization system on pediatric dosing and equipment size determination: a crossover trial involving simulated resuscitation events. Arch Pediatr Adolesc Med 2003;157(3):229-236.

17. Luten RC, Wears RL, Broselow J, Zaritsky A, Barnett TM, Lee T, et al. Length-based endotracheal tube and emergency equipment in pediatrics. Ann Emerg Med 1992;21(8):900-904.

18. Lubitz DS, Seidel JS, Chameides L, Luten RC, Zaritsky AL, Campbell FW. A rapid method for estimating weight and resuscitation drug dosages from length in the pediatric age group. Ann Emerg Med 1988;17(6):576-581.
19. Lanoix R, Golden J. The facilitated pediatric resuscitation room. J Emerg Med 1999;17(2):363-366.

20. Mace SE, Bern AI. Needs assessment: are disaster medical assistance teams up for the challenge of a pediatric disaster? Am J Emerg Med 2007;25(7):762-769.

21. Rosenberg M, Greenberger S, Rawal A, Latimer-Pierson J, Thundiyil J. Comparison of Broselow tape measurements versus physician estimations of pediatric weights. Am J Emerg Med 2011;29(5): 482-488.

22. Fineberg SL, Arendts G. Comparison of two methods of pediatric resuscitation and critical care management. Ann Emerg Med 2008; 52(1):35-40.

23. Miyoshi E, Fujino Y, Mashimo T, Nishimura M. Performance of transport ventilator with patient-triggered ventilation. Chest 2000; 118(4):1109-1115.

24. Blakeman TC, Toth P, Rodriquez D, Branson RD. Mechanical ventilators in the hot zone: effects of a CBRN filter on patient protection and battery life. Resuscitation 2010;81(9):1148-1151.

25. Campbell RS, Johannigman JA, Branson RD, Austin PN, Matacia G, Banks GR. Battery duration of portable ventilators: effects of control variable, positive end-expiratory pressure, and inspired oxygen concentration. Respir Care 2002;47(10):1173-1183.

26. Rodriquez D Jr, Branson RD, Barnes SA, Johannigman JA. Battery life of the "four-hour" Lithium ion battery of the LTV-1000 under varying workloads. Mil Med 2008;173:792-795.

27. Blakeman TC, Rodriquez D, Branson RD. Accuracy of the oxygen cylinder duration calculator of the LTV-1000 portable ventilator. Respir Care 2009;54(9):1183-1186.

28. Rubinson L, Vaughn F, Nelson S, Giordano S, Kallstrom T, Buckley $\mathrm{T}$, et al. Mechanical ventilators in US acute care hospitals. Disaster Med Public Health Prep 2010;4(3):199-206.

29. National Commission on Children and Disasters. 2010 report. http:// cybercemetery.unt.edu/archive/nccd/20110427002908/http:/ www.childrenanddisasters.acf.hhs.gov/index.html. Accessed July 8, 2011.

\section{Discussion}

Walsh: While I was working at an all-children hospital, they considered the concept that part of our training should be how to take care of adults. The feeling was that, as a standalone children's hospital, parents may not use good judgment or agree to leave their kids and might collapse in the children's hospital, with no place for them to go. If they're both injured at the same time in a disaster, we have to be prepared to take care of the parent as well. Does that make sense?

Branson: If you ask me, that doesn't make sense. Cincinnati Children's Hospital, which is one of the largest in the country, with more than
500 beds, is within blocks of several adult hospitals: Good Samaritan has more than 600 beds, University Hospital has more than 500 beds, and the Christ Hospital has more than 600 beds. There's lots of adult capacity and very little pediatric capacity, and I think it is much more likely to find a pediatric patient in an adult ICU than an adult patient in a pediatric ED.

It's important for all of us to understand how to care for pediatric patients, but I've never done a PALS [pediatric advanced life support] certification, and if they brought in a 4-year-old, I would ventilate with pressure ventilation but I wouldn't know what the right $V_{T}$ is. I guess I'd do $6 \mathrm{~mL} / \mathrm{kg}$ if I could figure out what the patient's weight is supposed to be. The ARDS Network's height/weight conversion table stops at 40 inches. Below that, what do I do? Having a critically ill kid in a community hospital could be a disaster, because they don't have the equipment to care for that patient.

DiBlasi: Let's say the proverbial meconium hits the fan, and large numbers of patients require mechanical ventilation. I noticed in your talk that all of the strategic national stockpile ventilators are being stockpiled in huge warehouses, and those ventilators have batteries. Are they plugged in continuously, intermittently, or do those batteries hold their charge for years?

Branson: The ventilators do not hold a charge for years. The Centers for Disease Control and Prevention is 
the expert in this. With the new ventilators there's a port to plug it in without opening the case. With the Impact 754 you have to open it up, and they employ biomedical engineers whose job is maintain and charge those ventilators for the appropriate period of time.

I can tell you about the Ohio stockpile. The state of Ohio bought about half Impact 754s and half LTV-1200s, and I was not involved in the buying decision, but I suggested they save some of the money for maintenance. The first time Mark Babic in Cleveland had some ventilators pulled from different spots around the state, the LTV-1200s would not even turn on: the battery and internal clock were both dead, and they wouldn't turn on at all. The Impact $754 \mathrm{~s}$ all had dead batteries, but if you plugged them in at least you could operate them. Maintenance is critical, and most people don't think about it.

Myers: So after learning that, the state of Ohio deployed a lot of those ventilators out to the hospitals. You got a free piece of equipment, but the theory is that you're plugging them in and doing the maintenance and keeping them up to snuff. We have about 10 in our facility that we do all the maintenance on, and when something goes wrong, we call the state to replace it. They're plugged in, they're utilized, they're run, and so if there's a disaster we'll deploy them wherever they need to go. I think we have 4 hours to get them boxed up and ready to go.

Branson: I think half of them are deployed in Ohio and the other half remain stockpiled. By deploying the ventilators around the state in different hospitals, those ventilators are maintained and the staff becomes familiar with the operation. That's a "win-win."

Gentile: Rich, how does the decision making process happen to buy the equipment? We probably wouldn't want to use some of these ventilators in adult care, let alone in pediatric or neonatal patients. How do the technical specifications guide what is purchased?

Branson: The decisions are very different. The Centers for Disease Control put together a group of mechanical ventilation experts. I believe that both adult and pediatric experts listened to a presentation about each device and had the opportunity to hands-on inspect the ventilators. And I think that was the correct process.

Unfortunately, the further you get down the line in the hierarchy of a state government, such as at the county or community level, the more likely the decision is made by an administrator or maybe an emergency medical technician. These individuals have been told by the state that they need to have 100 ventilators. Some of the lowcapability, inexpensive devices get selected because the person making the decision typically views the ventilator as something that's used only in CPR [cardiopulmonary resuscitation]. That's an important problem. Even sophisticated people might buy a lot of something that will probably never work and just pray they'll never need to use it, as opposed to buying a smaller number of ventilators that surely will work, because they think it may look like they didn't try to meet the needs of a larger number of patients.

My suspicion is that we'll run out of beds before we run out of ventilators. I know the disaster medical assistance team guys do great things, and in North Carolina they have a big semitruck the side of which opens up and it's like an ICU, but that's not enough surge capacity. I think the people who we need to care for critically ill patients are going to be in the hospital. If we had, say, 50 ventilated patients and ventilators for all of them, well, then what? What would we do for intravenous fluids? We don't think about all the things we can just reach for in the ICU. Critical care for a large num- ber of patients outside the hospital is a huge challenge, it's just not going to happen unless you bring in the military and they helicopter in a full hospital.

DiBlasi: In the disasters you mentioned, how many pediatric patients were mechanically ventilated? I suspect that a lot of patients would die in a large mass-casualty event, so would there be much need for mechanical ventilation or intensive respiratory therapy?

Branson: Regarding the September 11, 2001, attack on the World Trade Center towers, in trauma we'd say that was an "upside-down" event. Usually you have about 5 or 6 times as many injuries as deaths, but in that event most of the people died and few patients required ventilation.

The problem in the New Orleans hurricane Katrina flood was that the emergency generators were on the first floor of the hospital, which was 9 feet below sea level, so they had no power, and they ran out of oxygen and ventilators. I don't know how many were pediatric patients. The critical care aeromedical transport teams will tell you that they flew a lot of adult and pediatric patients on ventilators out of New Orleans. They hand-ventilated most of the patients on the way up to the roof and the helicopter. ${ }^{1}$ deBoisblanc said that most of the pulse oximeters' batteries had died, and he was actually okay with that because then he had no idea how low the oxygen saturation was on his way up to the roof.

1. deBoisblanc BP. Black hawk, please come down: reflections on a hospital's struggle to survive in the wake of Hurricane Katrina. Am J Respir Crit Care Med 2005;172(10): 1239-1240.

DiBlasi: Let's say that these stockpiled ventilators work well in adults, but we don't know if they work well in pediatric patients. Could we remove adult patients from ventilators that we 
know work well in pediatric patients and support the majority of the pediatric patients who require ventilation, and just have the adults ventilated with the stockpile ventilators only? Is there any plan for that?

Branson: Not that I' $m$ aware of, and I think the short answer is no. In the SARS [severe acute respiratory syndrome] epidemic in Canada they discovered that, even though we're all very collegial, inside your own city when you start talking about trading staff or bringing staff or equipment from your hospital to theirs, it's not nearly as cooperative as you might think. There are all kinds of legal issues.

If they ship these ventilators out, I hope the LTV-1200s go to the pediatric hospitals, because the Impact 754 and LP10 are not as pediatric-friendly. The Impact 754 is accurate at low $\mathrm{V}_{\mathrm{T}}$ when powered with $50 \mathrm{psig}$ air or oxygen, but when running on the compressor, the manual recommends not delivering a $\mathrm{V}_{\mathrm{T}}<300 \mathrm{~mL}$. The work of breathing with the LP10 is high, and I doubt pediatric patients could spontaneously breathe with it.

DiBlasi: When the Department of Defense was evaluating pediatric-capable mass-casualty ventilators, and each group came in and tested them on the lung models, were they static models, spontaneously breathing, or both?

Branson: I do not know, but would guess they were all static.

Dalton: I think my experience may be biased by the fact that I was in Washington DC when a lot of this was being arranged. In my hospital we got a lot of grant money to develop disaster planning for our hospital. We have ventilators and other things stockpiled, but the only way any of this is ever going to work, I think, is if people at the local level already have a plan in place.

Hurricane Katrina showed us that we can't wait until the government comes in 3 weeks later. How many of us even know if our hospitals have stockpiles? One of the challenges is how to triage patients. New York did a good analysis of what they would do in a mass-casualty event such as a bioterrorism attack, and they created a triage model that included how they would take patients off the ventilator. How many of us have that built into our practice?

In many countries, if a patient needs to be ventilated, hand ventilation is provided by the parents in a lot of situations. I think sometimes we're so technology-oriented that we forget that possibility. In the polio epidemic that's how survival went up, with those students in Copenhagen. That's something we should keep in our back pockets. But how many of us have stockpiles and a disaster plan in our hospitals and are ready to go?

Branson: You have to have a disaster plan or your hospital can't get Joint Commission accreditation. I wouldn't buy a single ventilator if the hospital, the emergency medical services people, and the police can't talk to each other on their radios. I'd fix communication before I ever bought a piece of hospital equipment.

We did a simulation of a problem at the airport, and for whatever reason the dispatchers routed the trauma patients to a private hospital that does mostly cardiac care and obesity surgery: I don't know why.

We always talk about hand-bagging. In Copenhagen the medical students took 4-hour shifts hand-bagging patients. But you have to remember that those people were paralyzed from po- lio; they didn't have ARDS from trauma or chemical inhalation with bronchospasm. The other problem with manual ventilation is if you have somebody with a contagious respiratory disease such as SARS.

Take the Canadian experience: the longer you were in the room, the more likely you were to get SARS. ${ }^{1}$ Some hospital personnel developed SARS early in the epidemic. A lot of that had to do with a simple problem in the training: they were wearing their mask in the room, but when they left the room they pulled off their gloves and reached for the mask at the nose to remove it. That's where all the bugs are, so they got it on their hands, and that's how they got sick.

I think the best triage tool comes from Ontario: they use the SOFA [Sequential Organ Failure Assessment] score. ${ }^{2}$ Everybody gets care, but patients with the highest SOFA score get comfort care. Some people have worried that we are going to run out to the nursing home and take people off ventilators and put them on ventilators in the ICU, but I don't see that happening. One of the big problems in a disaster is all of these people at home. If you have your insulin in the fridge and there's no power, that's a problem, if you've got an oxygen concentrator at home, that's a problem. Those are the patients that we don't want to come to the hospital in a disaster, but we need somewhere to take care of them.

1. Loutfy MR, Wallington $T$, Rutledge $T$, Mederski B, Rose K, Kwoiek S, et al. Hospital preparedness and SARS. Emerg Infect Dis 2004;10(5):771-776.

2. Christian MD, Hawryluck L, Wax RS, Cook T, Lazar NM, Herridge MS, et al. Development of a triage protocol for critical care during an influenza pandemic. CMAJ 2006;175(11):1377-1381. DOI: 10.1503/ cmaj.060911. 